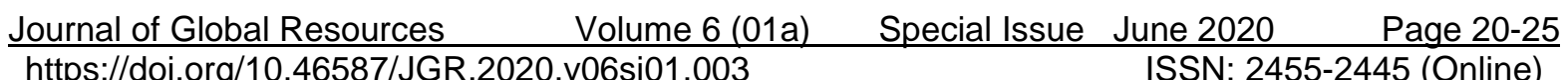

03

\title{
GOVERNMENT INTERVENTION OR SOCIAL INNOVATION: UNDERSTANDING HOW TAIWAN IS COPING WITH COVID-19 AND DEVELOPING RESILIENCE THROUGH ITS SOCIAL INFRASTRUCTURE SERVICES
}

\author{
Chiamei Hsia \\ Partner for Community Development at Arizona State University, USA \\ Email: chsia2@asu.edu
}

\begin{abstract}
While the spread of Covid-19 seems to slow down after months of global turmoil, numerous experts suspect the battle of Covid-19 has not settled yet as confirmed asymptomatic cases increasing and the pending pressure of resuming economic activities, which may expose fragile communities to the second wave of outbreak. Expecting lengthy combat to this treacherous disease, it is imperative to seek solutions keeping the balance between pandemic containment and social wellbeing. Taiwan, among a few nations, has controlled the Covid-19 outbreak and maintains a relatively stable society. This article aims to understand how Taiwan is coping with the Covid-19 global crisis and developing resilience through its social infrastructure services. By using the Covid-19 crisis management as a case study in Taiwan, this article analyses the ways of social infrastructure services, government intervention, grassroots public administration, private sector collaboration, industry flexibility, and social cohesion contributing to successful crisis management.
\end{abstract}

Key words: Social Infrastructure Services, Crisis Management, Grassroots Public Administration, Social Innovation, Social Cohesion

\section{Introduction}

While infections of Covid-19 are elevating exponentially in Europe and the U.S. after the outbreak of coronavirus pandemic and having over 6 million confirmed cases; Taiwan, the island of 23 million, garners global attention for its effective epidemic intervention despite its geographic proximity, economic tie, and frequent direct flights to mainland China. Based on the real-time world statistics- World meter [1]. Taiwan has a relatively low rate of Covid-19 infection by May 20, 2020, as of 440 cases compared with the USA over 1,582,000, Spain near 280,000, and the UK approaching to 250,000 cases. To tackle this global crisis, Taiwan took proactive measures from policymaking to implementation to contain community transmission and prevent the Covid-19 outspread. Seeking pertinent factors of Taiwan's successful outbreak control in this global pandemic crisis, this article aims to identify key elements that attribute to the effective containment, prevention of social panic, as well as the balance between quality of life and activity restriction.

\section{Recognizing the Crisis and Precautious Action}

Despite the diplomatic isolation and blocked outside of the World Health Organization (WHO) by China, Taiwan quickly took action to contain the spread of coronavirus at the early stage of the outbreak. Taiwan officials began to board and inspect passengers for fever or pneumonia symptoms on a direct flight from Wuhan on December 31, 2019. Right after the first confirmed case of the novel coronavirus, the border control and travel restrictions took place. The crosssector coordination among multiple government agencies soon formed the disease battlefront in January 2020 (Two Experts from Taiwan visit Wuhan, 2020).

Such early alert and vigilant reaction to the coronavirus was due to a harsh lesson learned from the SARS epidemic in 2003. The arbitrary lockout approach in the Heping Hospital at Taipei City without appropriate measures caused 24 civilian deaths with one committed suicide within 97 citizen infections; and 7 medical staff deaths within 57 medical personnel infections (Chang, 2020). Although China was criticized for delays of reporting to the WHO on SARS, the inexperienced medicine personnel and lack of disease control specialty in the state level resulted in the high rate casualty and marked the darkest era of Taiwan medicine history. Adopting the suggestions by 
Centers for Disease Control and Prevention (CDC) experts from the US, the Taiwan government established the National Health Command Center (NHCC) in 2004 in response to public health emergencies (Chiang, 2020, para.18).

The scepticism with data from China (Yun, 2020) and crisis management experience learned from the last SARS epidemic (Piper, 2020) contribute to the effective measures in Taiwan in response to this global crisis. As soon as the Taiwanese health authorities recognized there were suspicious cases of a new type of virus spreading in China, the officials began to wonder whether it is SARS again (Piper, 2020). Dr. Chang-chuan Chan, dean of the College of Public Health at the National Taiwan University, considered the bitter experience from the SARS epidemic as a critical factor weighed in actions of the proactive measures. The Covid-19 testing capacity in Taiwan is also noted among other nations. Only a couple days after the release of the genetic sequence of the Covid-19 on January 11, the Testing and Vaccine Center at the Taiwan Centers for Disease Control (CDC) developed the instant diagnostic kit that is able to shorten one-day testing time to 4 hours (Chiang, 2020, para.7). Recently, the National Health Research Institutes (NHRI) announced the success of 15-minutes rapid test result for Covid-19 and prepared for mass production with diagnostic kit manufacturers [2]. In addition to swift responses to the Covid-19 pandemic, the single-payer health care systems, sufficient medical infrastructure, and advanced technology are also crucial components helping to contain the outbreak (Yun, 2020).

\section{Medicare-for-All, Taiwan single-payer health care system}

Launched in 1995, the National Health Insurance (NHI) program, equivalent to the idea of Medicare-for-All is one of the most significant social programs ever undertaken in the history of Taiwan (Lu \& Chiang, 2011). The NHI benefits are quite comprehensive: it ranges from dental care to hospital care; prescription drugs cover from Western medicine to traditional Chinese medicine; and provide various health services from preventive services to elderly home care (Wu et al, 2010). In addition to the comprehensive health care services, the low copays (range from 12-18 USD for doctor visiting), good accessibility (patients can see any doctor without a referral), nationwide research databank (open resources for research purpose, public health monitoring, and policy implementation evaluation), and up to $99 \%$ population coverage rate (Wu et al, 2010) all contribute to early infection cases diagnosis and proactive patients seeking-out measures. In this Covid-19 pandemic outbreak, Taiwan leveraged the NHI database and integrated it with the immigration and customs database to help case identification (Wang et al, 2020). During a clinic visit, doctors can more efficiently take necessary measures based on patient's travel history and clinical symptoms.

The health care infrastructure in Taiwan also plays an imperative role to control the situation. Negative pressure isolation rooms, which are used to contain airborne contaminants, are particularly critical in this Covid-19 crisis. In Taiwan, there are 1,100 negative pressure isolation rooms while Japan has 1870 rooms. Considering the population of two different regions, Taiwan has 40 rooms per million population compared with the counterpart in Japan with 15 rooms per million (Chiang, 2020, para.26). Meanwhile, hospitals are also seeking collaboration with professionals and industries to maximize facility capacity. In the wake of the Covid-19 pandemic, Taiwanese scientists have developed portable devices with heat exchange technology that enables them to turn regular isolation rooms into negative pressure rooms with affordable cost (Wu, 2020).

\section{Effective Collaboration of Public and Private Sectors}

Upon the early infection cases confirmed, Taiwan government began to ban the masks export and launched the name-based mask rationing system to secure mask availability to every residents; nevertheless, the mask demand has tripled as public sentiment growing tense. Foreseeing the growing mask demand, the Taiwan government invested NT\$ 180 million [3] (US\$ 6 million) to purchase the mask-making machines and recruited a team of around 100 technicians helping machinery assembly at a site to expedite the mask-making process. It aims to expand up to 60 supply lines in addition to the extant supply lines and maximize the mask production up to 10 million per day to fulfil Taiwan's daily-base needs ( $\mathrm{Li}, 2020)$. These machines will be distributed to 15 mask manufacturers to boost daily mask production as 10,000 marks per machine. By early March, Taiwan has become the world's second-largest mask producer (Formosa TV English News, 2020). 
Such manufacturing industry capacity and flexibility are deeply rooted in Taiwan's economic development strategy back to early 1960s, an export-orientation economy system that was dominated by small and medium-sized enterprises (SMEs) encouraged by the Taiwan government (Hamilton, 2018). The "Made in Taiwan" labels in the 1970s were as ubiquitous as "Made in China" are today (Rigger, 2011). The transition from traditional manufacturing to high-tech manufacturing from the 1980s to 2000s marked another significant era in Taiwan's manufacturing industry. From original equipment manufacturing (OEM) to original design manufacturing (ODM), Taiwan's manufacturing industry, especially in information technology, had a significant share in the global economy (Rigger, 2011).

The government's investment in Research and Design (R\&D) projects, state-sponsored research institutes, and a variety of funds and incentive policies for private enterprises, all contributed to the industry transformation. Taiwan's government-sponsored research institutes, such as the Industrial Technology Research Institute and Institute for Information Industry, often implemented the research projects and transferred the research outcomes to the industry for commercialization under the policies (Intarakumnerd \& Liu, 2018). This collaborative relationship between public and private sectors has its industrial base and cultural context. In this Covid-19 crisis, the expansion of mask manufacturing, rapid testing kit development and production well demonstrate such unique partner relationship between public and private sectors when it comes to a nationwide crisis.

\section{Strict Quarantine Measures with Technology Aids and Social Infrastructure Support}

To prevent a large-scale outbreak, the Taiwan Centers for Disease Control (CDC) has implemented a strict quarantine policy. The mandatory quarantine is applied to people who have exposed to the confirmed Covid-19 infection cases. Local health organization officials will follow the protocols to track people under the mandatory quarantine with an electronic monitoring system and check their health condition. Working with the telecom carriers, the government uses the smartphone for location tracking to enforce an effective quarantine (Smith, 2020). The system monitors phone signals and will signify an alert when those under the mandatory quarantines move away from their home or turn off their phones. Health organization officials will call twice a day to check their health condition and ensure people under the quarantine are with their phones. According to the officials of Taiwan's Department of Cyber Security, the police and local officials will contact or visit those who trigger an alert within 15 minutes. This measure has successfully controlled the spread of the Covid-19.

An expanded quarantine policy took place and was applied to travellers who had been traveling in countries on the level three travel alert list or transferred flight in the airports of China, Hong Kong and Macao (Su, 2020). This extension results in a more quarantine population and requires a larger social infrastructure to support and implement the quarantine protocols. By April 6 , the number of people put under quarantine is over 110,000 and testing the social infrastructure capacity. To implement quarantine policy successfully, advanced technology provides imperative tools for efficient management; however, sufficient social infrastructures also play critical roles to contain the outbreak and prevent social panics. In this second wave of quarantine, it follows the same quarantine protocols with local support from community and local district administration officials instead of health organization staff. The chair of the Li-office [4] and the Li-officials [5] of regional District Hall [6] are mobilized to assist government conducting health condition checking and location tracking for those put to the quarantine. This grassroots public administration service helps immensely containing the Covid-19 pandemic outbreak. Through phone interviews with several Li-office chairs from different districts in Taichung City [7], the Covid-19 crisis has relatively limited impacts on daily life in Taiwan. Although local economic activities are slowing down and big events are being cancelled, irrational purchasing and social panics are not the case in Taiwan as the confirmed Covid-19 infection cases are slowing down to zero by April 14, 2020[8].

\section{Social Cohesion and Civic Vigilance}

In response to the coronavirus epidemic, residents in Taiwan demonstrate a relatively collaborative attitude and trustfulness toward the government's proactive measures and public policies. In the strategy of recruiting hotels as additional quarantine facilities, the public shows positive feedback to quarantine hotels and has confidence in their public health management. Evidence shows that 
more hotels are willing to join the quarantine hotel recruitment and opt to publicize their hotels online [9]. Meanwhile, the government also provides subsidies for people in need of staying at quarantine hotels. For foreign visitors, businesspersons, frequent travellers, or residents who have difficulty finding appropriate accommodation for quarantine, the quarantine hotels provide alternative options to diminish social tension and anxiety.

To manage a seamless collaboration between the public and private sectors, it relies on citizens' confidence in the government and social cohesion to support the policies compliance. Transparency of policymaking process, daily information updated, social infrastructure accessibility for support and resources, and officials' prompt response to local needs all help to cultivate people's trust to the government. At the beginning of the Covid-19 outbreak, the government's proactive measures such as inspecting passengers on direct flights from Wuhan in December, activating the Central Epidemic Command Centre, travel ban implementation, and securing masks supplies to every resident in Taiwan have helped to build government's credibility and competency in the national crisis management. As a return, the government gets more civic support and collaboration. Upon the announcement of the executive order for mask requisition before boosting mask-making production, the policy has drawn only few complaints from mask manufacturers. One of the mask suppliers explained that the requisition order actually relieved the pressure of overwhelming mask demand from an array of requests varied from wholesalers, affiliated companies, families, or even friends ( $\mathrm{Li}, 2020)$. Meanwhile, the name-base mask rationing system and mask mapping application help to ensure every resident getting masks, diminish social panics and efficiently avoid mask stockpiling for profit-making.

While implementing the strict quarantine policy, the Taiwan government did not announce stay home order but managed to educate the public with updated knowledge and information to advise residents a better way of practicing their daily routines with awareness and precaution. The civic vigilance is cultivated through a variety of communication means including press conferences, news reports, television, and popular social media such as Facebook and LINE [10]. Residents will receive updated domestic Covid-19 confirmed cases, the global Covid-19 situation, prevention instruction through the daily press conference hosted by the Central Epidemic Command Centre, the official health organization websites, and the interactive Pandemic Gate Keeper Application [11] for social media or LINE users through their mobile devices. Social distancing and maskwearing in public have become social norms on daily life bases. This strategy seems proved to be effective when evidence shows there is no confirmed domestic Covid-19 transmission by April 16 ensuing Qingming holidays[12] when the public began to resume ordinary recreation activities three months later after the Covid-19 outbreak (Y.A. Chen, 2020).

\section{Conclusion: Government Intervention or Social Innovation}

To evaluate the effective result of Taiwan's Covid-19 crisis management, we should expand our analytical lens other than government intervention perspective, such as social innovation, in order to get a better understanding of its success in the complexity of social structure, economic practices, political stance, and cultural context. Social innovation, in the absence of consensus on a clear definition, inevitably emerges as an alternative approach to resolve new social problems in response to the third industrial revolution characterized by rapid development, globalization, crossborder economic activities, increasing complexity in international trade, political interest and cooperative network (Heiskala, 2007). As a novel approach to examine the regional or state level resilience capacity when confronting new social challenge spawned by globalization, the Taiwan's Covid-19 experience can be studied as a social innovation model to explore what key determinant factors contribute to its success. To some extent, the global Covid-19 pandemic unearthed the vulnerability and challenges of globalization in relation to the public health, sustainability in the manufacturing industry, local resilience and trustfulness building. Most reports and articles attribute Taiwan's success in the Covid-19 containment to its proactive and comprehensive measures through a strong and responsive state; nevertheless, we would like to extend the analytical lens to a wider social structure spectrum. Consideration of community networks, grassroots public administration services, economy system, social capital and civic culture among other social constructs may also help to delineate a better picture of Taiwan's resilience capacity in response to global crisis. Taiwan seems to create its own unique moderate model balancing between free- 
market capitalism practice and government regulation; civic freedom and strong state governance; as well as western liberalism and traditional Chinese culture.

Forecasting when the coronavirus outbreak will end is not easy. Public health experts define the "end" of Covid-19 when the daily death rate drops below 0.3 per million as an indicator to predict a possible timeframe for the end of this pandemic. Nevertheless, the end of the pandemic may not be equivalent to the back of normal life. The supply chain breaking, travel restrictions, social distancing, and behaviour change may still apply to the post-pandemic daily life before the effective vaccination or enough people developing immunity through infection (Gallagher, 2020). Our societies are still vulnerable as we disproportionally rely on the global supply chain and lack of sufficient social infrastructure. Foreseeing the lengthy combat to this pandemic crisis, lessons from Taiwan may help us to tackle this global crisis while securing the public health without compromising our quality of life and balancing between restricted economic activities and civic wellbeing.

\section{References}

1. Hamilton, G.G \& Kao, C.S. (2018). Making Money: How Taiwanese industrialists embraced the global economy. California: Stanford University Press.

2. How a team of technicians is helping Taiwan triple mask production. (2020 Mar 25). Taiwan News. Retrieved from https://www.taiwannews.com.tw/en/news/3903970

3. Intarakumnerd, P.\& Liu, M.C. (2019). Industrial technology upgrading and innovation policies: A comparison of Taiwan and Thailand. In K. Tsunekawa \& Y. Todo (Eds.) Emerging States at Crossroads (pp.119-143). Springer: Singapore.

4. Lu, J.R. \& Chiang, T.L. (2011). Evolution of Taiwan's health care system. Health Economics, Policy and Law, 6, p.85-107.doi:10.1017/S1744133109990351

5. Rigger, S. (2011). Why Taiwan matters: Small Island, global powerhouse. Maryland: Rowman \& Littlefield.

6. Smith, N. (2020, Feb 3). Taiwan uses smartphone to monitor patients quaranitined over virus scare. The Telegraph. Retrieved from https://www.telegraph.co.uk/news/2020/02/03/ taiwan-uses-smartphones-monitor-patients-quarantined-virus-scare/

7. Two experts from Taiwan visit Wuhan to understand and obtain information on severe special infectious pneumonia outbreak; Taiwan CDC raises travel notice level for Wuhan to Level 2(2020, Jan 20). Taiwan Centers for Disease Control. Retrieved from https://www.cdc.gov.tw/En/Bulletin/Detail/jFGUVrlLkluHmzZeyAihHQ?typeid=158

8. Wang, C. J., Ng, C.Y., Brook, R. H. (2020). Response to COVID-19 in Taiwan: Big data analytics, new technology, and proactive testing. Journal of the American Medical Association, 323(14), p.1341-1342.

9. Wang, M.Y. \& Yuan, B. JC. (1999). Evaluation practice of the government-sponsored programme for promoting industrial upgrading in Taiwan, Science and Public Policy, Volume 26, Issue 2, April 1999, Pages 125-135. Retrieved from https://doi.org/10.3152/ 147154399781782518

10. Wu, T.Y., Majeed, A., Kuo, K.N. (2010). An overview of the healthcare system in Taiwan. London Journal of Primary Care, 3(2): p.115-119. doi: 10.1080/17571472.2010.11493315

11. Yan, H.D., Chiang, C., \& Chien, C. (2014). "From Original Equipment Manufacturing to Branding: Entrepreneurship, Strategic Leadership, and Taiwan's Firm Transformation" International Entrepreneurship and Management Journal 10: p.81-102.

12. Su, C.W. (2020, Feb 10). 懶人包/居家隔離, 居家檢疫, 自主健康管理有何差異?一圖看懂! [Illustration for dummy: What are the differences among At-Home (mandatory) Quarantine, At-Home Quarantine, and Self-Monitoring Health Management?]. Business Today. Retrieved https://www.businesstoday.com.tw/article/category/80392/post/202002100014/

13. Formosa TV English News. (2020, Feb 16). Taiwan to become the world's second-largest mask producer by early March [Film clip]. Retrieved from https://www.youtube.com/ watch?v=r8vevXvvx7Y

14. Chiang, H.W. (2020, Feb 24). 新冠病毒䇻檢從一天變 4 小時,背後功臣是位於昆陽站的神秘 實驗室 [Secret laboratory Kun-yang station expedites coronavirus testing from one day to 4 
hours]. Common Wealth. Retrieved from https://www.cw.com.tw/article/articleLogin.action? from $=$ search\&id $=5099106$

15. Li, T.H. (2020, Mar 5). 台灣 2020 口罩之戰:總人口數 2300 萬日產量挑戰 1000 萬 [Taiwan 2020 mask challenge: How a nation of 23 million population daily produces 10 million mask]. BBC News. Retrieved from https://www.bbc.com/zhongwen/trad/chinese-news51734215

16. Piper, K. (2020, Mar 10). Taiwan has millions of visitors from China and only 45 coronavirus cases. Here's how. Vox. Retrieved from https://www.vox.com/future-perfect/2020/3/10/ 21171722/taiwan-coronavirus-china-social-distancing-quarantine

17. Chang, T.W. (2020, Mar 12). 重返和平-SARS 隔離黑洞中難以告別的記憶 [Heping hospital retrospection-An unforgettable black hole memory of SARS quarantine time]. The Reporter. Retrieved from https://www.twreporter.org/a/sars-memories-life-under-quarantine-inheping-hospital

18. Yun, M. (2020, Mar 12). How Taiwan is containing coronavirus-despite diplomatic isolation by China. The Guardian. Retrieved from https://www.theguardian.com/world/2020/mar/13/ how-Taiwan-is-containing-coronavirus-despite-diplomatic-isolation-by-china

19. Gallagher, J. (2020, Mar 23). Coronavirus: When will the outbreak end and life get back to normal? BBC News. Retrieved fromhttps://www.bbc.com/news/health-51963486

20. Wu, Y.S. (2020, Mar 25). 15 萬元就能改造負壓病房! 台教授研發新空調技術, 防疫超前部署 [Advancing anti-coronavirus strategy- Air-conditioning innovation by Taiwanese professor helps to equip hospitals more negative pressure rooms to combat pandemic with 15,000 NT\$]. Business Next. Retrieved from https://www.bnext.com.tw/article/57056/taiwannegative-pressure- air-condition-debut

\section{Foot Note References}

[1] https://www.worldometers.info/coronavirus/

[2] NHRI News. Retrieved from http://www.nhri.org.tw/NHRI_WEB/nhriw001 Action.do? status= Show_Dtl\&nid=20200408125246900000\&uid=20081204954976470000

[3] Some sources indicate an amount around NT\$ 200 million.

[4] $\mathrm{Li}$ (里), equivalent to the village in rural areas, is the basic unit of administration district for voting and public service in the urban area of Taiwan. The chair of Li-office is generated through direct voting.

[5] Served as secretary of the chair of Li-office and liaison between the Li-office and regional District Hall, the Li-official is in charge of assisting the chair of Li-office for public policy implementation, reflecting the local voices, and reporting the feedback from the community.

[6] Regional District Hall, similar to Township in rural areas, the public service area for each district hall encompasses around 30-40 Li district units.

[7] Located in the central of Taiwan, Taichung City is the third-largest city in Taiwan; and encompasses the economic- and modern- orientated features of northern Taiwan as well as agricultural-based and traditional value context of southern Taiwan.

[8] https://www.cdc.gov.tw/

[9] https://health.tvbs.com.tw/medical/323375

[10] LINE, equivalent to WhatsApp in US and WeChat in China, is a free and popular messaging application for smartphone and other mobile devices in Taiwan.

[11] Named as 疾管家, this application is designed to provide informative materials for an array of pandemic diseases circulated in Taiwan other than Covid-19.

[12] There are four days off from April 2 to April 5 with two days of traditional festivals and weekends in Taiwan. People begin to resume some outdoor activities and big gatherings after three months of public activity restriction. 